\title{
BJMHR
}

British Journal of Medical and Health Research

Journal home page: www.bjmhr.com

\section{Antimicrobial Activity of Aspergillus Gliotoxin on S.aureus in Diabetic's Patient's Type-2}

\author{
Anaam F, Eptissam Y.Pirko, Adawia F.Abaas, Burooj M. Razooqi Al-aajem \\ 1.Department of Microbiology, College of Science, Diyala University, Diyala, Iraq. \\ 2. Department of Microbiology, College of Medicine, Diyala University, Diyala, Iraq.
}

\section{ABSTRACT}

Diabetes mellitus is a serious public health problem, $S$. aureus is the most common bacteria isolated from ulceration of diabetic patients, and increase the risk of $S$. aureus carriage in patients with diabetes may reflect association between diabetes and bacterial carriers. The aim of the study was to estimation rate of $S$. aureus carrier in diabetic's patients type-2 and determine antimicrobial effect of Gliotoxin on previous bacterial carriage in type-2 diabetes.

The study was conducted on 450 diabetics' patients, attended the out patients clinic in Baquba Teaching Hospital, their ages ranged from15-65years, with mean age of 36.15, who were randomly selected, during the period from May 2016 to April 2017, patients were classified into two groups according to type of diabetes, group1 included: 184 with type1-diabetes, and group2 included 266 with type2-diabetes, 97 patients with foot ulcers. Swabs were taken from anterior nares, toe and axillae for each diabetic patient type-2, identified based on standard bacteriological methods. Using Kirby-Bauer method for detection antibacterial effect of Gliotoxin. The results showed rates of bacterial carriage in anterior nares of type2diabetic patients without complications were (11.4\%), (4.4\%), respectively for S. aureus and $M R S A$, in type-2 diabetes with complications were (8.6\%),(2.1\%) respectively for $S$. aureus and MRSA. The study showed the Aspergillus fumigatus Gliotoxin was effective against $S$. aureus and MRSA carrier in diabetics patients type- 2 with foot ulcer, for $S$. aureus inhibition diameter was $(20.50,16.40,12.20) \mathrm{mm}$ for different concentrations of Gliotoxin, to MRSA was $(8.25,6.1,4.20) \mathrm{mm}$. Its antibacterial effect was directly proportional with its concentration According to the values of MIC \& MBC, the results revealed that the Gliotoxin of Aspergillus fumigatus were more effective as antibacterial agent against $S$. aureus and $M R S A$. Increasing rate of $S$. aureus carrier in diabetic patient's type-2 which lead to a significantly increased risk of bacterial infections. Gliotoxin was effective as antibacterial agent against $S$. aureus in type-2 diabetes .

Keywords: Diabetes type-1, diabetes type-2, S. aureus nasal carriage, Aspergillus fumigatus, Gliotoxin (GT). 


\section{INTRODUCTION}

Diabetes mellitus is a serious public health problem in worldwide [1]. Infections with diabetes are one of the leading causes of human mortality. It represents a severe complication of diabetes and the most common cause of diabetes associated hospital admissions [2]. Diabetes is a chronic infection occurs when pancreas yield in sufficiently amount of insulin and may when the body cannot efficiently use the insulin [3]. S. aureus are the most common bacteria isolated from ulceration of diabetes [4], chronic leg ulcers affect1-2\% of the general population and are related to increased morbidity and health costs [5]. The pathology resulting from $S$. aureus infections is of great importance due to growing resistance to antimicrobial agents [6,7].Multiple studies have also detected the presence of bacteria and the polymicrobial nature of chronic, non-healing wounds, and the frequency of $S$. aureus infections has to be high [8,9]. S. aureus is able to produce biofilms and to express antimicrobial resistance and a variety of virulence factors such as surface proteins, endotoxins, and exoenzymes which enhances its virulence [10]. The increased carriage in patients with diabetes may reflect association between diabetes and risk factors found in the general population such as, bacterial carriers among diabetic patients [11]. The increasing association of multi-drug resistant bacteria with diabetic foot ulcers is the most problem .Initial therapy of diabetic foot infections is frequently fastidious because reliable culture data is lacking [12]. Aspergillus fumigatus is known to produce various mycotoxins including Gliotoxin, that is an alkaloid with a low molecular size, and possess number of immunosuppressive activities [13]. Antimicrobicidal activity cytokine release by leukocytes and T-lymphocyte-mediated cytotoxicity it is genotoxic and also causes apoptosis in macrophages. That is biologically active secondary metabolites causing serious risks for human and animal health [13].

\section{MATERIALS AND METHOD}

The study was conducted on 450 diabetic patients ascertained from a variety of sources, attended the out patients clinic in Baquba Teaching Hospital, their ages ranged from 1565years, during the period from May 2016 to April 2017 in Baquba city in Iraq, patients were classified into two groups according to type of diabetes, group1 included: 184 with type 1diabetes, and group 2: included 266 with type2-diabetes, 97patients with foot ulcer .Swabs were taken from anterior nares for each diabetic patient type-2, the specimens were inoculated on Blood agar and Mannitol salt agar plates by streaking methods for isolation of aerobic bacteria, incubated aerobically at $37 \mathrm{C}$ for 48 hour, the isolates were identified based on standard bacteriological methods.[14]. Using Kirby-Bauer method for detection antibacterial effect of Aspergillus fumigatus Gliotoxin(GT) that performed and extraction 
with slight modifications with $50 \mathrm{ml}$ of chloroform and extracts by thin layer chromatography technique (TLC) according to [15]. Statistical analysis: -This tool calculates the $\mathrm{z}$ score of the mean of a single sample.

\section{RESULTS AND DISCUSSION}

The study was conducted on 450 diabetic patients ascertained from a variety of sources , attended the out patients clinic in Baquba Teaching Hospital, their ages ranged from 1565years, during the period from May 2016 to April 2017 in Baquba city in Iraq . Patients were classified into two groups according to type of diabetes, group1 included: 184 with type 1-diabetes, and group2: included 266 with type2-diabetes, 97 patients with foot ulcers. Swabs were taken from anterior nares for each patient with type-2diabetes for detection bacterial carriers. The results as showed in table-1 explains rates of bacterial carriage in anterior nares of type-2diabetes without complications were $21(11.4 \%)$ and $4(2.1 \%)$ respectively for $S$. aureus, MRSA, rates of bacterial carriage in type-2 diabetes with complications were16 (8.6\%), 4(2.1\%) respectively for $S$. aureus, MRSA, as explain in table-2. The study showed the Aspergillus fumigatus Gliotoxin was effective against $S$. aureus and MRSA carrier in diabetics patients type-2 with foot ulcer as in table-3, for $S$. aureus inhibition diameter was $(20.50,16.40,12.20) \mathrm{mm}$ for different concentrations of Gliotoxin, to MRSA was $(8.25,6.1$, 4.20) $\mathrm{mm}$.

Table 1 The rate of $S$. aureus, MRSA carriage in anterior nares of diabetics patients type-2 groups.

\begin{tabular}{llll}
\hline $\begin{array}{l}\text { Bacteria } \\
\text { Total no.185(100) }\end{array}$ & $\begin{array}{l}\text { Type-2 diabetes without } \\
\text { complication 62(33.5) }\end{array}$ & $\begin{array}{l}\text { Type-2 diabetes with } \\
\text { complication 34(18.5) }\end{array}$ & P value \\
\hline Staphylococcus aureus & $21(11.4)$ & $16(8.6)$ & 0.05 \\
Methicillin Resistance & $8(4.4)$ & $4(2.1)$ & 0.06 \\
S.aureus & & & \\
\hline
\end{tabular}

Table 2 Inhibition zone ( $\mathrm{mm}$ ) of Gliotoxin on S.aureus and MRSA carrier in type-2 diabetes.

\begin{tabular}{lllll}
\hline Bacteria & $\mathbf{2 m g} / \mathbf{m l}$ & $\mathbf{4 m g} / \mathbf{m l}$ & $\mathbf{6 m g} / \mathbf{m l}$ & $\mathbf{8 m g} / \mathbf{m l}$ \\
\hline Staphylococcus aureus & 20.50 & 16.40 & 12.20 & 16.0 \\
Methicillin resistance S.aureus & 8.25 & 6.1 & 4.20 & 8.2 \\
\hline
\end{tabular}

Table 3 Values of MIC and MBC of Aspergillus fumigatus Gliotoxin on bacteria isolated from type-2 diabetic patients.

\begin{tabular}{lll}
\hline Bacteria & MIC & MBC \\
\hline Staphylococcus aureus & 2 & 4 \\
Methicillin resistance S.aureus & 4 & 6 \\
\hline
\end{tabular}

Diabetes and it complications was chronic and non-healing due to several factors such as bacteria were the predominant pathogens in the diabetic infections especially ulcers [12], our 
study revealed the high prevalence rate of bacterial carriage was observed especially in type-2 diabetes with foot ulcer. $S$. aureus was the most common bacteria of community and hospital-acquired infections that can cause morbidity and mortality, S. aureus nasal carriage vary between diabetic patients but increased in type-2 diabetes [13]. Increase risk of S. aureus and multidrug resistance bacteria especially MRSA carriage in patients with diabetes may association with many factors such as obesity, old age, in appropriate previous antibiotics treatment and prolonged hospital stay, and state for several months [15].

\section{CONCLUSION}

Increasing rate of $S$. aureus carrier in diabetic patient's type-2 which lead to a significantly increased risk of bacterial infections. Gliotoxin was effective as antibacterial agent against $S$. aureus in type-2diabetis.

\section{REFERENCES}

1. Shaw JE, Scree RA, Zimmer PZ. Global estimates of the prevalence of diabetes for 2010 and 2030 Diabetes .Res Clin Pract .2009; 87: 4-14.

2. Lavery L, Armstrong D, Murdoch D. Validation of the Infectious Diseases Society of America's diabetic foot infection classification system. Clin Infect Dis.2007; 44(4): $562-565$.

3. Prompers L, Huijberts M, Schaper N, Apelqvist J, Bakker K, Edmonds M, Holstein P, Jude E, Jirkovska A, Mauricio D, et al. Resource utilization and costs associated with the treatment of diabetic foot ulcers. Dialectology.2008; 51:1826-1834.

4. Thomas GW, Rael TL, Bar-Or R, Shimonkevitz R, Mains CW, Slone DS, et al. Mechanisms of delayed wound healing by commonly used antiseptics. Journal of Trauma. 2009; 66: 82-91.

5. Munckhof WJ, Nimmo GR, Schooneveld JM, Schlebusch S, Stephens AJ ,Williams $\mathrm{G}$, et al. Nasal carriage of S.aureus, including community-associated methicillinresistant strains, in Queensland adults. Clinical Microbiology and Infectious Diseases.2009; 15,149-155.

6. Naimi TS, LeDell KH, Como-Sabetti K, Borchardt SM, Boxrud DJ, Etienne J, Johnson SK, Vandenesch F, Fridkin S. Comparison of community- and health care associated methicillin-resistant S.aureus infection. JAMA. 2003;290 , 2976-2984.

7. Keen EF, Robinson BJ, Hospenthal DR, Aldous WK, Wolf SE, et al .Incidence and bacteriology of burn infections at a military burn center. Burns 2010; 36: 461-468.

8. Frank DN, Wysocki A, Specht-Glick DD, Rooney A, Feldman RA, et al. Microbial diversity in chronic open wounds. Wound Repair Regan .2009;17: 163-172. 
9. Gontcharova V, Youn E, Sun Y, Wolcott RD, Dowd SE. Acomparison of bacterial composition in diabetic ulcers and contralateral intact skin. Open Microbiol J. 2010; 4: 8-19.

10. Fazli M, Bjarnsholt T, Kirketerp-Moller K, Jorgensen B, Andersen AS, et al. Nonrandom distribution of Pseudomonas aeruginosa and S.aureus in chronic wounds. J Clin Microbiol .2009; 47: 4084-4089.

11. Van BA, Verkaik NJ, de-Voge CP, Boelens HA, Verveer J, Nouwen J, et al. Reclassification of S.aureus nasal carriage types. The Journal of Infectious Diseases.2009; 199, 1820-1826.

12. Erman, D. S., Schaefler, S., Simberkoff, M. S., \& Rahal, J. J. (1987). S. aureus colonization in intravenous drug abusers, dialysis patients, and diabetics. The Journal of Infectious Diseases, 155, 829-831

13. Pardo J, Urban C, Galvez EM, Ekert PG, Muller U, and et al. the mitochondrial protein Bak is pivotal for gliotoxin-induced apoptosis and a critical host factor of Aspergillus fumigatus virulence in mice. J Cell Biol.2006; 174: 509-519.

14. Collee JG, Fraser AG, Marmion BP, Simmons A. Mackie and McCartney practical medical microbiology. 14th Ed. New Delhi: Churchill-Livingstone; 2006.

15. Andrews JM. BSAC standardized disc susceptibility testing method (version 7). Journal of Antimicrobial Chemotherapy, 2008, 62:256-278. 17.

\section{BJMHR is}

- Peer reviewed

- Monthly

- Rapid publication

- Submit your next manuscript at editor@bjmhr.com 